IZA DP No. 9170

A Signal of Diligence? Student Work Experience and Later Employment Chances

Stijn Baert

Olivier Rotsaert

Dieter Verhaest

Eddy Omey

July 2015 


\title{
A Signal of Diligence? Student Work Experience and Later Employment Chances
}

\author{
Stijn Baert \\ Ghent University, University of Antwerp, \\ Université catholique de Louvain and IZA \\ Olivier Rotsaert \\ Ghent University \\ Dieter Verhaest \\ KU Leuven (Campus Brussels) and Ghent University \\ Eddy Omey \\ Ghent University
}

Discussion Paper No. 9170

July 2015

IZA
P.O. Box 7240
53072 Bonn
Germany

Phone: +49-228-3894-0
Fax: +49-228-3894-180
E-mail: iza@iza.org

Any opinions expressed here are those of the author(s) and not those of IZA. Research published in this series may include views on policy, but the institute itself takes no institutional policy positions. The IZA research network is committed to the IZA Guiding Principles of Research Integrity.

The Institute for the Study of Labor (IZA) in Bonn is a local and virtual international research center and a place of communication between science, politics and business. IZA is an independent nonprofit organization supported by Deutsche Post Foundation. The center is associated with the University of Bonn and offers a stimulating research environment through its international network, workshops and conferences, data service, project support, research visits and doctoral program. IZA engages in (i) original and internationally competitive research in all fields of labor economics, (ii) development of policy concepts, and (iii) dissemination of research results and concepts to the interested public.

IZA Discussion Papers often represent preliminary work and are circulated to encourage discussion. Citation of such a paper should account for its provisional character. A revised version may be available directly from the author. 
IZA Discussion Paper No. 9170

July 2015

\section{ABSTRACT}

\section{A Signal of Diligence? Student Work Experience and Later Employment Chances}

We investigate the impact of student work experience on later hiring chances. To completely rule out potential endogeneity, we present a field experiment in which various forms of student work experience are randomly disclosed by more than 1000 fictitious graduates applying for jobs in Belgium. Theoretical mechanisms are investigated by estimating heterogeneous treatment effects by the relevance and timing of revealed student work experience. We find that neither form of student work experience enhances initial recruitment decisions. For a number of candidate subgroups (by education level and occupation type), even an adverse effect is found.

JEL Classification: J24, I21, D83, C93

Keywords: student employment, transitions in youth, human capital, signaling, randomised field experiments

Corresponding author:

Stijn Baert

Ghent University

Sint-Pietersplein 6

9000 Gent

Belgium

E-mail: Stijn.Baert@UGent.be 


\section{Introduction}

In many OECD countries, student employment, i.e., any form of paid work by students during the summer or academic year, is the norm for a majority of youngsters in secondary and tertiary education (Adriaenssens et al., 2014; Orr et al., 2011). From society's point of view, student employment provides a flexible source of labour but risks crowding out regular work. From the point of view of an individual student employee, income from student work may help to satisfy consumption and investment aspirations. However, the effect of students' work decisions on their economic attainment may go beyond the short term due to the impact of these decisions on their (schooling and) later labour market outcomes. Therefore, the question is whether providing general incentives to combine study and work - an increasingly common practice among many OECD countries (Alam et al., 2013) - is an effective policy orientation. Gaining some deeper understanding of whether, why and when student employment contributes to favourable labour market outcomes is necessary in order to answer this question in the proper way.

Over the past few decades, scholars have utilised general (economic) theoretical frameworks to understand how student work may affect later labour market success (Geel and Backes-Gellner, 2012; Hotz et al., 2002; Molitor and Leigh, 2005; Ruhm, 1997). First, student employment may directly enhance an individual's human capital by enabling her/him to gain relevant work experience, practical life skills, labour market abilities and relevant knowledge from business exposure. Following standard Human Capital Theory, these skills and knowledge may lead to additional returns on the labour market (Becker, 1964; Painter II, 2010). However, based on the same theory in combination with the Theory of the Allocation of Time (Becker, 1965), a negative effect might also be expected. This is the case, as maintaining substantial employment schemes during the academic year may 
interfere with learning and academic performance (Buscha et al., 2012; Derous, 2008; Dustmann and van Soest, 2007; Kalenkoski, 2012; McCoy and Smyth, 2007). In other words, there might be a time-use trade-off between working and studying. Second, following Signalling Theory (Spence, 1973), employers might use student work as a signal of intrinsic work motivation and ability. In particular, work experience during the academic year might be a strong signal, as only highly capable students can manage to combine study and work successfully. However, employers might also (mis)interpret student work experience in a candidate's CV as a signal of liquidity constraints (therefore, adverse social background characteristics) and especially in the case of student work unrelated to the field of study disinterest in academic development. This second channel is thereby closely related to Arrow's (1973) model of Statistical Discrimination. Third, according to Social Network Theory (Granovetter, 1973), student workers may collect valuable market information and establish personal relationships helping them to find a better job match more quickly later on in their career. Lastly, following Screening Theory, one's performance in a student job might affect the probability of being hired by the same employer due to on-the-job screening (Stiglitz, 1975). Employers who hire student workers may gather information about these individuals' productivity and attitudes.

Empirical evidence on the effect of student employment on later labour market outcomes is mixed, although mostly a non-negative effect is found. Carr et al. (1996), Ehrenberg and Sherman (1987) and Parent (2006) note no substantial effect of work experience during high school and college on later wages in the short- and long-term in the United States and Canada. In contrast, Alam et al. (2013), Häkkinen (2006), Light (1999, 2001) and Ruhm (1997) find a (short-lived) positive effect on wages and/or employment in Sweden, Finland and the United States. In addition, Geel and Backes-Gellner (2012) find a positive effect on wages in Switzerland, but only for student employment related to the field of study. Last, Molitor and Leigh (2005) 
show that returns on student employment vary by education level: returns tend to be higher in the United States for college graduates than for high school graduates. One exception to the tendency of non-negative effects is the results of Hotz et al. (2002). These authors report a zero effect of student work in secondary education and a negative effect (except for African Americans) of student work in tertiary education in the United States.

It is doubtful whether the aforementioned empirical results can be given a causal interpretation. Obviously, engagement in student work is endogenous with respect to later labour market outcomes. Naively estimated effects of the former variable on the latter variable may reflect variation in factors such as general ability and motivation. These factors are unobservable to the researcher but may influence both the likelihood of student work experience and the probability of later labour market success. However, the aforementioned contributions use instrumental variables estimation techniques at best to tackle this problem. More concretely, these IV studies use local labour market conditions as an instrument. The use of such instruments might be, in our opinion, problematic because students may already have begun a job search during their last year(s) of school; thus, labour market conditions during education may affect transition to work success at least indirectly via drop-out decisions and (hence via) human capital accumulation (Rees and Mocan, 1997). One exception is the work of Hotz et al. (2002), who use an ambitious semi-structural approach. In their model, identification is achieved from the assumption that unobservable determinants of labour market outcomes are, after controlling for social background, orthogonal to accumulated schooling at the age of 13 . This is a strong assumption.

In addition to the fact that this literature is inconclusive with respect to whether student work experience affects later employment outcomes, it is characterised by two other gaps. In the conclusion of his seminal study, Ruhm 
(1997) wrote, in regard to directions for future research: "In particular, it is important to better understand the mechanisms by which the [student] employment raises economic attainment, the role of job characteristics of the positions held by in-school youths, and the nature and sources of demographic group differences in the returns to student employment." However, 18 years later, there is still a dearth of serious attempts to fill this gap, i.e., to investigate why and when student employment might also "work" later on in the labour market. On the one hand, to our knowledge, no study has focussed on explicitly examining the empirical salience of the four theoretical channels outlined above. Although unravelling their exact relative importance seems impossible, investigating particular predictions of these models should be feasible. On the other hand, little is known about the heterogeneity of the effect with regard to qualitative aspects of student work experience (for instance, the relationship of work experience to the field of study).

In the present study, we aim to occupy parts of the three aforementioned gaps in the literature on student work experience and later labour market outcomes. More concretely, we investigate the causal connection between various forms of student work and later hiring chances for graduates. To this end, we present a randomised field experiment, in which quartets of fictitious job applications from graduates are sent to real vacancies in Flanders (Belgium). Within each quartet, these applications are equal in terms of jobrelevant characteristics (including human and social capital). For every vacancy, three applications are randomly assigned a treatment of former student work, mentioned within the candidate's CV and motivation letter. One of these "treated" applications reveals student work unrelated to the field of study during the summer, one discloses student work related to the field of study during the summer, and the last reveals student work unrelated to the field of study during the academic year. The overall treatment effect, i.e., the extent to which employers reward student work experience, is then captured by measuring the relative call-back for treated and control 
individuals.

First, with the outlined experimental design, the endogeneity of student work is completely controlled by construction. As employers' decision-making information is under our control, and the treatment of student work experience is randomly assigned to the fictitious job applicants, selection on unobservables is not an issue. Thereby, our results can be given a causal interpretation. Second, with respect to the "when" question, the research design allows us to estimate heterogeneous treatment effects with regard to (i) whether the work was combined with study tasks during the academic year and (ii) the relevance of student work with respect to the candidate's field of study (and thus to the job announced in the vacancy). Third, our research design enables us to provide suggestive evidence with respect to the empirical power of the aforementioned theoretical channels underlying the effect of student work on later labour market outcomes. As candidates within our experiment apply by construction for a position with an employer outside their network, a non-zero treatment effect can only indicate that the aforementioned Human Capital or Signalling channels play a role in employment decision-making. In addition, a relative surplus ${ }^{1}$ of the various forms of student work may provide insights into these two channels' relative importance. More concretely, as mentioned before, we assume that a relatively higher surplus of student work during the academic year (instead of during the summer) is consistent with the Signalling channel. Based on the Human Capital channel, in contrast, a similar surplus could be expected for similar student jobs (unrelated to the job mentioned in the vacancy) during the summer and the academic year in a case wherein educational level is kept constant. $^{2}$ Conversely, both channels are consistent with a relatively

\footnotetext{
${ }^{1}$ Throughout this article, "surplus" refers to surplus in terms of (additional) positive call-back.

${ }^{2}$ Alternatively, one could assume that based on the Human Capital channel, a relatively lower surplus could be expected for this type of (former) student worker, given the more outspoken trade-off between learning and working during the academic year. Following this assumption, however, finding a higher
} 
higher surplus for student work related to the field of study and thereby to the occupation mentioned in the vacancy (instead of unrelated work). This type of work has the potential to yield both more relevant human capital and a signal of sincere interest in the posted job.

\section{Experiment}

\subsection{Building on the Correspondence Experimentation Framework}

To answer our research question, we built on the correspondence experimentation framework of Bertrand and Mullainathan (2004). Within this type of experiment, pairs of fictitious job applications are sent to real job openings. These applications differ only in the characteristic that is to be tested. By monitoring subsequent call-back, unequal treatment based on this characteristic can be identified. This method is the golden standard for identifying unequal treatment in the labour market as employer discrimination is disentangled from supply-side determinants of labour market outcomes. Selection on unobservables is not an issue as all the employer's decision-making information is under the researcher's control (Riach and Rich, 2002; Pager, 2007). Recent correspondence experimental designs were used to study unemployment duration dependence and the labour market penalty of motherhood (Baert, 2014; Eriksson and Rooth, 2014; Kroft et al., 2013).

In our extension of this framework, we sent a quartet of fictitious job applications - one control candidate and three treated candidates - to real vacancies in Flanders. To this end, for each tested occupation, we constructed

surplus for student work during the academic year would be even more supportive of the Signalling channel. 
four (suitable) comparable job application templates for male graduates, only differing in details and by lay-out. For each vacancy, we randomly assigned four identities with respect to student work to one of these template types and sent the four resulting combinations in a randomised order to the employer. Thereafter, reactions from the employer side were analysed to investigate the surplus of the three different student work treatments.

\subsection{Job Application Templates}

We aimed to apply for starter jobs in four occupations: (i) the (middle-)lowskilled administration-oriented occupation of administrative clerk, (ii) the (middle-)low-skilled industry-oriented occupation of operator, (iii) the (middle-)high-skilled administration-oriented occupation of management assistant and (iv) the (middle-)high-skilled industry-oriented occupation of laboratory analyst. Testing multiple occupations (rather than just one) is important because it enables us to avoid the danger inherent in many former correspondence experiments in which a researcher simply selects an occupation with, potentially, a high (or low) surplus of the tested characteristic. In addition, due to the particular occupations chosen, we were able to measure heterogeneous treatment effects by required skill level and the secondary versus tertiary sector orientation of the occupation.

Because we had to send four experimental identities to each vacancy, the aim to test four occupations resulted in the need to create 16 application templates. For each occupation, four types of templates (type 'A', type 'B', type ' $\mathrm{C}$ ' and type 'D') comprising a CV and motivation letters matching the general requirements of starter jobs within the aforementioned occupations were constructed. Type A, B, C and D job application templates were, at the occupation level, identical concerning all job-relevant characteristics but differed concerning inessential peculiarities and lay-out to avoid detection. To ensure that our applications were realistic and representative, example 
CVs and motivation letters from the Public Employment Agency of Flanders were calibrated for our purposes.

All fictitious applicants were single males born, living and studying in Ghent; the second largest city of Flanders, with approximately 249,000 inhabitants. Those candidates applying for (middle-)low-skilled positions were 18 years old and those applying for (middle-)high-skilled positions were 21 years old. All applicants had graduated from the same type of school, with a comparable reputation, in June 2014. The candidates applying for a starter job as an administrative clerk graduated from technical secondary education with a degree in commerce. Those applying for a job as an operator held a vocational secondary education degree. The (middle-)high-educated applicants applying for a position as a management assistant held a Bachelor's degree in management assistance. Those applying for a position as a lab analyst held a Bachelor's degree in chemistry. To avoid employers' detection of the experiment, a variety of common wordings were used for these degrees (with, for instance, variation in redundant mentions of the technical orientation of the secondary education degree and the professional orientation of the Bachelor's degree, and variation in mentions of "office management" as the field of the degree of management assistant applicants).

In addition, we added to all applications the following features: a typically Flemish sounding first name and surname; a Belgian nationality; an address with an existing street name but a non-existing house number in a middleclass neighbourhood; an email address and a telephone number from major providers; a birthdate in 1996 or 1993; adequate Dutch, French and English language skills; comparable computer skills; one or two practised sports and one or two practised cultural activities. The $\mathrm{CV}$ and motivation letter templates are available upon request.

It is important to note that the minimal differences between type A, B, $\mathrm{C}$ and D job application templates could not bias our results as the treatment 
of interest, i.e., student work experience, was, for each vacancy, randomly assigned to these types. Moreover, the regression analysis presented in Section 3 shows that these differences did not yield different call-back outcomes for these four types.

\subsection{Experimental Identities}

In Belgium, student employment is permitted from the age of 15 . Since 1 January 2012, students are able to work 50 days per year under a student employment contract. The only tax that has to be paid for student work is a uniform social security contribution amounting to $8.1 \%$, of which $2.7 \%$ is charged to the student worker and $5.4 \%$ to the employer (Source: Belgian Federal Public Employment Service, Labour and Social Dialogue). ${ }^{3}$ Our own calculations based on the SONAR data covering the transition from school to work for two representative cohorts of 3,000 Flemish youngsters born in 1978 and 1980 show that $71 \%(83 \%)$ of these youngsters had at least one student job during secondary (tertiary) education. Student work in Europe is concentrated during the summer holidays and, for a majority of students, is not related to their field of study (Adriaenssens et al., 2014; SONAR, 2003, 2005). Allen (2011) shows that the dominance of this type of job is somewhat more pronounced in Belgium than in other European countries.

To contribute not only to the whether-gap but also to the why- and whengaps in the literature on student work experience and later labour market outcomes, in our experiment, we not only compared hiring outcomes between the control identity with no student work experience and one (homogeneous) treatment identity with work experience but also distinguished between three

\footnotetext{
${ }^{3}$ With respect to regular employment, the employer's social security contribution amounts $35.0 \%$ in Belgium, while the employee's social security amounts 13.1\% percent (Source: Belgian Federal Public Employment Service, Labour and Social Dialogue).
} 
treatment identities. Figure 1 visualises the added value of this approach.

\section{$<$ Figure 1 about here. $>$}

First, for each vacancy, apart from the control applicant, one candidate applied disclosing the most common student work experience, i.e., not related to the study field and during the summer. By comparing call-backs for this identity to those for the control applicant, we are able to measure the effect of revealing (the most common form of) student work experience with respect to interview invitations and other positive reaction probabilities.

Second, an application from a candidate with student work experience unrelated to the field of study but during the academic year was sent to the same vacancies. This allows us, when comparing outcomes for this identity to those for the first mentioned treatment candidate, to measure the surplus of student employment during the year (instead of during the summer). As mentioned in Section 1, a relatively higher surplus for this identity would be in favour of the Signalling channel because these candidates disclose (more) their ability to manage a combination of study and work successfully.

Lastly, an application revealing student work related to the field of study and during the summer was submitted. Introducing this last identity enables us to identify the surplus of student work relevance. As mentioned in Section 1, based on both the Human Capital and Signalling channels, a more beneficial student work surplus is expected for this last experimental identity.

With the exception of the control identity, we gave all candidates two "doses" of treatment, i.e., two years in which student work was done. Student employment occurred in 2011 and 2012 (those with job application template types A and D) or 2012 and 2013 (those with types B and C). Work experience was mentioned both in the motivation letter and in the CV itself. In the motivation letter, one sentence was added revealing whether student work was performed, whether this was done during the summer or the 
academic year and whether this work experience was related to the field of study (and thereby to the posted job). ${ }^{4}$ In the $\mathrm{CV}$, a section labelled "experience" (job application template type A), "work experience" (template type B), "student employment" (template type C) or "work experience as a student" (template type D) was included. ${ }^{5}$ The experimental identity with student work experience related to his field of study mentioned - depending on the occupation for which he applied - experience as an administrative coworker, operator, assistant of the deputy secretary or lab assistant. The experimental identities with an experience that was not related to their studies mentioned experience as a cashier at an American fast food company (job application template type A), waiter at a brasserie (template type B), sandwich artist at a second American fast food company (template type C) or bartender at a café (template type D). In addition, it was always indicated whether the student job was undertaken during the summer or academic year.

\subsection{Randomisation Procedure}

We conducted our experiment over the course of half a year, i.e., between

${ }^{4}$ For application templaye type A, the sentence "My work experience is limited to student work [during the summer] [during the academic year] [(related to my studies and to the job you posted) during the summer]" was added. For template type B, the following sentence was adopted: "As you can read, I was active as a [student worker during earlier summers] [student worker during earlier academic years] [student worker in a job related to your vacancy during earlier summers]". For template type C, the sentence "Moreover, I [did summer work in July 2012 and July 2013] [combined my studies with student work in 2012 and 2013] [did summer work as a(n) administrative co-worker/operator/assistant of the deputy secretary/lab assistant in July 2012 and July 2013]". Lastly, for template type D, the following sentence was included: "In addition, I did [summer work as a bartender] [student work during the academic year as a bartender] [summer work as a(n) administrative co-worker/operator/assistant of the deputy secretary/lab assistant]".

${ }^{5}$ Based on the sentence included in the motivation letter, as well as for job application template types A and B, it became clear that the mentioned (work) experience was gathered via student work (and not via regular work). In addition, "student job" or "holiday work" was explicitly added between parentheses when reporting the particular experience within the "experience" or "work experience" component of the $\mathrm{CV}$. 
October 2014 and March 2015. During this period, we selected all vacancies for starter jobs in the occupations of administrative clerk, operator, management assistant and lab analyst in the database of the Public Employment Agency of Flanders for which our fictitious job applicants matched the requirements. To avoid detection, we applied to no more than one vacancy from each employer. In total, we were able to send 1008 applications to 252 vacancies. One control and three treatment applicants were sent to 70 vacancies for administrative clerk, 62 vacancies for production worker, 70 vacancies for management assistant and 50 vacancies for lab analyst.

Upon the identification of a suitable vacancy, we assigned the four experimental identities to type A, B, C and D job application templates in the following way. First, we generated a random number for each identity. Then, the identity with the highest number was assigned to the type A template, the identity with the second highest number to the type B template, and so on.

Subsequently, we sent the resulting combinations to employers, each time with 12 to 24 hours in between submissions. The order in which the combinations were presented to the employers was determined by four additional random numbers, one for each of the experimental identities. The identity with the highest number was sent first, the identity with the second highest number was sent second, and so on.

Table 1 provides the reader with an overview of the frequencies with which the experimental identities were assigned to a particular job application template type and a particular place in submission order. Clearly, our randomisation procedure worked well. Each experimental identity was assigned to each potential job application template type and each potential place in the submission order in approximately $25 \%$ of the vacancies.

$<$ Table 1 about here. $>$ 


\subsection{Experimental Outcomes}

Reactions from (real) employers to our fictitious candidacies were received by telephone voicemail and email. The content of employers' responses is available upon request. To minimise inconvenience to the employers, we immediately terminated the recruitment procedure after getting a positive reaction. All call-backs received later than 30 days after the date of application submission were discounted.

In our analysis, we distinguish between two definitions of positive callback. Positive call-back sensu stricto means that the applicant was invited for an interview concerning the job for which he applied. Positive call-back sensu lato includes, in addition to the former definition, the receipt of an alternative job proposal and a request to provide more information or to contact the recruiter.

\subsection{Research Limitations}

Before reporting and discussing our empirical findings, we discuss four limitations identified in our experimental design. For an in-depth discussion of the ethical aspects of the correspondence experimentation framework, we refer to Riach and Rich (2004).

The most important limitation of this study is its focus on a particular but determining - labour market outcome, i.e., initial hiring decisions of employers (outside the candidates' network). Because we simply measure call-back rates for first interviews, we cannot translate our research results into divergences in job offers, let alone divergences in wages. The only method that could be used to obtain causal measures of the surplus of student work experience at later stages of the recruitment process we are aware of is audit testing. Audit experiments go one step further than correspondence experiments by sending matched actors to job invitations. This method is, 
however, currently only seldom used, as it has been criticised on various grounds (Heckman and Siegelman, 1993; Riach and Rich, 2002). The main critique is that audit tests suffer from the problem of finding and successfully training real-life job applicants so that they represent a true perfect match. In addition, auditors might (sub)consciously be motivated to prove unequal treatment based on the tested ground and might therefore adjust their behaviour accordingly in an interview.

As a result of this first limitation, in comparison with the literature on student work experience and employment outcomes mentioned in Section 1, we completely eliminate the endogeneity problem at the cost of giving up on scope. Nevertheless, our experimental design is effective in investigating options to explain why and how student work experience might affect broader labour market outcomes.

A second limitation is related to the former point because it also has repercussions for the generalisability of our findings. We measure the (potential) surplus of student work only for young, male candidates within the jobs posted in the database of the Public Employment Agency of Flanders. This limitation is, however, less acute in our design in comparison to former correspondence experiments as we made the conscious choice to test both industry- as administration-oriented and both (middle-)low as (middle-)high skilled occupations. However, it is still possible that the surplus of student work is more or less present in other occupations than those covered in this study.

Third, in line with the literature, we give no direct indication of the control candidate's treatment status. Therefore, the control applicant in our experiment could also be a treated candidate not disclosing his student work experience. The comparison of candidates with and without student work experience is therefore actually a comparison of "openly former student workers" and candidates with an unrevealed student work status. However, 
because this limitation is expected to cause a similar shift in the surplus of all treated experimental identities, this fact should not bias the conclusions with respect to the relative surplus of various forms of student work experience. The same is true for the second mentioned limitation.

Lastly, although we ensured that the "look and feel" of our CV and motivation letter templates was different for type A, B, C and D job application templates, it is possible that some employers discovered that they were being tested. However, we are quite convinced that the fraction of employers that detected the experiment, if any, was negligible. On the one hand, had employers detected the experiment, one could expect them to have complained about it or given some indication of their discovery. Yet, we did not receive any suspicious reaction in this respect. On the other hand, as student employment is, as a ground for unequal treatment, not heavily debated (in contrast to, for example, ethnicity and gender) in Belgium, we do not believe that employers would ever imagine they were being tested on this issue.

\section{Results}

Table 2 presents positive call-back rates measured for our control and treated job candidates. In Panel A and Panel B we follow positive call-backs in both the strict and broad sense, respectively. Overall statistics following the former (latter) definition are presented in Panel A.1 (Panel B.1). Candidates who do not reveal any student work experience receive an invitation for a job interview (any positive reaction) in $6.7 \%(18.7 \%)$ of cases while all candidates revealing student work experience together receive an invitation in $6.2 \%$ (16.7\%) of cases. The ratio of these call-back rates, presented in Column (6), is 0.922 with respect to positive call-back sensu stricto, indicating that the latter candidates receive $7.8 \%$ fewer invitations. It is 0.894 with respect to 
positive call-back sensu lato, meaning that those revealing student work experience receive, in addition, $10.6 \%$ fewer positive reactions in the broad sense. However, none of these ratios is significantly different from 1 . Thus, overall, mentioning student work experience does not yield a surplus with respect to the probability of getting a beneficial reaction to one's application. In other words, we cannot reject that, overall, disclosed student work experience is neglected as a discriminating criterion in respect to employers' application judgments.

\section{$<$ Table 2 about here. $>$}

In addition, separate interview rates for the three treated experimental identities are very comparable. The probability of receiving a job interview invitation is $6.3 \%$ for the identity with student work experience during the summer that is not related to his field of study, $6.3 \%$ for the identity with student work experience during the academic year that is not related to his field of study and $5.9 \%$ for the identity with student work experience during the summer that does relate to his field of study. Concerning the positive call-back rates in a broad sense, Columns (3) to (5) of Table 2 present somewhat more variation. Among the treated identities, the positive callback rate in a broad sense is the highest for those with unrelated student work experience during the academic year $(18.3 \%)$ and lowest for those with related student work experience during the summer (15.1\%). We come back to the significance of this difference later.

In Panels A.2 and B.2, Panels A.3 and B.3 and Panels A.4 and B.4 in Table 2, the dataset is broken up by candidate's education level, the orientation of the profession (administration or industry) and the contract type offered (permanent or temporary), respectively. In so doing, we obtain three subsamples for which positive call-back ratios are found which are (weakly) significantly lower than 1 . On the one hand, we observe that interview rates are less beneficial for former student workers who are more 
highly educated. ${ }^{6}$ On the other hand, we see that, with respect to the probability of getting any positive reaction, lower interview rates are compensated by more other positive reactions for these treated candidates. Moreover, for this broader outcome, we identify a significant ratio (below 1) for less educated candidates. Lastly, we find significant evidence that disclosing student work experience in the industrial sector (occupations of operator and lab analyst) has a negative effect.

Table 3 provides the reader with additional positive call-back ratios. While Column (6) of Table 2 is focussed on a comparison of the control candidates with all treated candidates, by means of Table 3 we are able to compare the difference in interview rates (Panel A) and (any) positive reaction rates (Panel B) between all experimental identities separately. Positive call-back ratios are calculated by dividing the positive call-back rate for the experimental identity indicated in the row header of Table 3 by the positive call-back rate for the experimental identity indicated in the column header. Only one weakly significant difference is observed in Table 3. The probability of receiving any positive reaction is $19.1 \%$ lower for candidates revealing student work experience related to his studies and performed during the summer.

\section{$<$ Table 3 about here. $>$}

Given the insignificant statistics presented in Table 3, we cannot reject that positive call-back rates for treated candidates are equal irrespectively of whether students did (irrelevant) jobs during the summer or during the academic year (Column (2) in Panel A.2 and Panel B.2) and of whether these jobs related to their field of study (Column (2) in Panel A.3 and Panel B.3).

\footnotetext{
${ }^{6}$ The reader might mention that, in addition, the magnitude of the interview ratio for the less educated is quite high. However, due to the low overall probability of interview invitation for the latter subpopulation (and ipso facto little overall variation in call-back for them), this does not yield a significant
} ratio. 
Based on this finding, taken together with the finding of an overall zero treatment effect, we conclude that our results do not support a (positive) human capital or signalling effect of student work experience with respect to employers' initial hiring decisions.

As we randomly assigned our four experimental identities with respect to student work experience to one of the application template types and places in the submission order, regressing positive call-back at the individual application level on the various forms of student work experience, on the one hand, and employee characteristics, on the other hand, should lead to exactly the same statistical results for a sample size approaching infinity. However, our sample size is finite. Therefore, variables that vary at the vacancy level (i.e., job application template type and submission order) may happen to correlate with the experimental identities. Table 1 indicates that this is indeed the case. For instance, candidates not mentioning student work experience are in $23.4 \%$ of cases assigned to the type A template while candidates mentioning student jobs related to their field of study are in $28.2 \%$ of the cases assigned to this template. In addition, the former identity is sent in $22.0 \%$ of the cases as a first application, while the latter is sent first to $24.2 \%$ of the vacancies. To control for this slight correlation, we perform a regression analysis.

In addition, by means of an ordered logistic regression, we are able to combine variation in the two studied outcomes, i.e., the probability of getting immediately invited to an interview after applying and the probability of getting any positive reaction. Therefore, we construct a dependent variable which is 2 in cases in which the candidate is immediately invited to a job interview, 1 in cases in which he receives any other positive reaction and 0 in cases in which he receives no (positive) reaction at all.

One final reason for conducting a regression analysis is that it allows us to investigate the independent effect of other vacancy characteristics by 
which the effect of student work experience is potentially heterogeneous (such as occupation level, occupation orientation or contract type mentioned in the vacancy).

Table 4 displays our model estimates presented as odds ratios. We regress the aforementioned categorical dependent variable on various sets of key and control variables, included as such and/or in interaction with student work experience. For reasons of regression results comparability, all variables except for the one indicating student work experience are normalised by subtracting their mean among the subpopulation of former student workers. Lastly, as four applicants contacted the same firm, their probability of receiving a positive reaction is correlated. Therefore, standard errors are corrected for the clustering of observations at the vacancy level.

\section{$<$ Table 4 about here. $>$}

In Model (1), we regress positive call-back on a dummy indicating student work experience only. In line with Column (6) in Panel A.1 and Panel B.1 of Table 2, we get an odds ratio that is non-significantly lower than 1. In Model (2) we add interactions between student work experience and indicators of whether this work was done during the year and of whether this work related to the job mentioned in the vacancy. The odds ratio for the former (latter) interaction is $1.108(0.890)$, thus indicating that the odds ratio comparing the positive call-back rates for candidates with and without student work experience is 1.108 times higher (1.124 times lower) in cases in which student work is performed during the academic year (related to the job mentioned in the vacancy). These ratios square with the relatively high call-back ratio in Column (1) of Panel B.2 (0.979 compared to 0.894 and 0.809) and the relatively low call-back ratios in Column (1) of Panel A.3 and Panel B.3 of Table 3. However, none of the aforementioned odds ratios are significantly different from 1.

Next, in Model (3), we combine the variables included in Model (2) with 
indicators of template type and submission order. However, the inclusion of these additional variables does not change the results for the treatment indicators. Moreover, as announced in Section 2.2, call-back outcomes do not vary across template types. Lastly, but not surprisingly, these outcomes are more in favour of the first candidate sent. For this candidate, the odds of a more beneficial outcome (invitation versus any other positive reaction and any other positive reaction versus no (positive) reaction at all) is 1.365 times higher compared with the last candidate sent. ${ }^{7}$

Finally, in Model (4), we extend the set of variables included as such and in interaction with student work experience (if relevant). On the one hand, we add a triple interaction indicating that student work experience was not related to the field of study and undertaken at an American fast-food restaurant (instead of at a small brasserie or café). On the other hand, we add interactions with indicators for (middle-)high educated candidates, vacancies in the industrial sector and vacancies offering a temporary contract. Consistent with Table 2, (only) a significant odds ratio is observed with respect to the interaction with the industrial sector.

To test the robustness of these regression results, we also estimated binary logit model and linear probability model regressions for both call-back outcomes separately. The results for these models lead to the same empirical pattern and are available upon request. Interestingly, regressions on positive call-back in a broad sense show that, also after controlling for job application template type and sending order, applicants who performed student work related to their field of study during the summer have a (weakly significantly) lower probability of getting a positive call-back in comparison to applicants not mentioning student work experience (as is also observed in Column (1)

\footnotetext{
${ }^{7}$ The call-back rates in a broad sense were $19.4 \%$ for the first, $17.8 \%$ for the second, $15.9 \%$ for the third and $15.5 \%$ for the fourth application sent.
} 
of Panel B.3 of Table 3).

\section{Conclusion}

This study contributed to the literature on student work experience and later labour market success. At the start of this study, we explained that a relationship between both outcomes could be expected based on standard Human Capital Theory as well as Signalling Theory, Social Network Theory and Screening Theory. In addition, we showed that the literature is, from an empirical point of view, inconclusive about whether (causality), why (empirical support for theoretical mechanisms) and when (heterogeneity in the effect by observables) student work may affect later labour market outcomes. By means of our own empirical research, we aimed to occupy parts of these three gaps. We did this by investigating the causal connection between various forms of student work and later hiring chances for graduates.

To this end, we presented a randomised field experiment in which quartets of fictitious job applications from male graduates were sent to real job openings in Flanders (Belgium). For every vacancy, a treatment of former student work was randomly assigned to three applications: student work unrelated to the field of study during the summer, student work related to the field of study during the summer and student work unrelated to the field of study during the academic year. By means of this experimental design, the endogeneity of student work with respect to later labour market outcomes was controlled by construction. Concerning the "when" question, this research design allowed us to estimate heterogeneous treatment effects with regard to (i) whether the student work was combined with study tasks during the academic year and (ii) the relevance of student work to the candidate's field of study. Lastly, we argued that an overall non-zero treatment effect (and a relatively higher effect in the case of relevant student work) could 
only be supported by the Human Capital and Signalling channels while a relatively higher surplus for student employment during the year would be in favour of the Signalling channel.

Overall, we found no evidence of a causal effect of mentioning student work experience on job candidates' probability of receiving a positive callback. In addition, we observed adverse effects for particular success rates for several subsamples of our data by education level, sector and contract characteristics. Thus, at the most, positive aspects of student employment (such as the signal of relevant skills and work motivation) compensated for its negative aspects (such as perceived adverse social background characteristics and disinterest in academic development). Moreover, the estimated treatment effect was not heterogeneous whether or not the graduate did his student work during the academic year (and thereby signalled that he was able to successfully manage a combination of study and work) nor did positive call-backs vary by whether students' (summer) jobs were related to their field of study.

Our empirical findings are inconsistent with the tendency of non-negative effects reported in the literature on student work and later labour market outcomes. This deviation can be explained in three ways. First, it is possible that the positive effects reported in the literature are partly driven by unobserved heterogeneity that is hard to control based on non-experimental data. Consistent with this explanation is that the single exception in the existing literature finding (partly) negative effects was precisely Hotz et al. (2002) applying the most ambitious - and in our opinion, the most convincing - approach to control for the endogeneity of student work with respect to later labour market outcomes. A second potential explanation is that the positive effects found in the literature were merely driven by the Social Network and Screening channels, which were locked out of our experiment.

One final explanation is related to one of the limitations acknowledged in 
our study, i.e., that we limited our scope to the effect of student work experience on a very particular labour market outcome. It is possible that the causal effect of student employment is higher at subsequent recruitment stages and during later points in the career. Therefore, as a direction for future research, we believe it could be fruitful to explore quasi-experimental data in which exogenous variation in students' work engagement (for instance, driven by lotteries assigning youngsters to (public) student jobs) is merged with administrative information on their later labour market outcomes. In that way, the strengths of the present study could be coupled to a broader focus.

\section{References}

Adriaenssens, S., Verhaest, D., Van den Broeck, A., Proost, K., Berings, D. (2014): De arbeidsparticipatie van Vlaamse scholieren. Tijdschrift voor Arbeidsvraagstukken, 30, 281-301.

Alam, M., Carling, K., Nääs, O. (2013): The effect of summer jobs on post-schooling incomes. IFAU Working Papers, 2013:24.

Allen, J. (2011): Mobilization of Human Resources. In: Allen, J., van der Velden, R. (eds.): The Flexible Professional in the Knowledge Society: New Challenges for Higher Education. Dordrecht, Heidelberg, London, New York: Springer.

Arrow, K. J. (1973): The Theory of Discrimination. In Ashenfelter, O., Rees, A. (eds.): Discrimination in Labor Markets. Princeton: Princeton University Press.

Baert, S. (2014): Career Lesbians. Getting Hired for Not Having Kids? Industrial Relations, 45, 543-561.

Becker, G. S. (1964): Human Capital: A Theoretical and Empirical 
Analysis, with Special Reference to Education. New York: National Bureau of Economic Research.

Becker, G. S. (1965): A theory of the allocation of time. Economic Journal, 75, 493-517.

Bertrand, M., Mullainathan, S. (2004): Are Emily and Greg more employable than Lakisha and Jamal? A field experiment on labor market discrimination. American Economic Review, 94, 991-1013.

Buscha, F., Maurel, A., Page, L., Speckesser, S. (2012): The Effect of Employment while in High School on Educational Attainment: A Conditional Difference-in-Differences Approach. Oxford Bulletin of Economics and Statistics, 74, 380-396.

Carr, R., Wright, J., Brody, C. (1996): Effects of High School Work Experience a Decade Later: Evidence from the National Longitudinal Survey. Sociology of Education, 69, 66-81.

Derous, E., Ryan, A. M. (2008): When earning is beneficial for learning: The relation of employment and leisure activities to academic outcomes. Journal of Vocational Behavior, 73, 118-131.

Dustmann, C., van Soest, A. (2007): Part-time work, school success and school leaving. Empirical Economics, 32, 277-299.

Ehrenberg, R. G., Sherman, D. R. (1987): Employment While in College, Academic Achievement, and Postcollege Outcomes. A Summary of Results. Journal of Human Resources, 22, 1-23.

Eriksson, S., Rooth, D.-O. (2014): Do Employers Use Unemployment as a Sorting Criterion When Hiring? Evidence from a Field Experiment. American Economic Review, 104, 1014-1039.

Geel, R., Backes-Gellner, U. (2012): Earning While Learning: When and How Student Employment is Beneficial. Labour, 26, 313-340. 
Granovetter, M. S. (1973): The Strength of Weak Ties. American Journal of Sociology, 78, 1360-1380.

Häkkinen, I. (2006): Working while enrolled in a university: does it pay? Labour Economics, 13, 167-189.

Heckman, J. J., Siegelman, C. (1993): The Urban Institute Audit Studies: Their Methods and Findings. Washington DC: Urban Institute.

Hotz, V. J., Xu, L. C., Tienda, M., Ahituv, A. (2002): Are there returns to the wages of young men from working while in school? Review of Economics and Statistics, 84, 221-236.

Kalenkoski, C. M., Pabilonia, S. W. (2012): Time to work or time to play: The effect of student employment on homework, sleep and screen time. Labour Economics, 19, 211-221.

Kroft, K., Lange, F., Notowidigdo, M. J. (2013): Duration Dependence and Labor Market Conditions: Evidence from a Field Experiment. Quarterly Journal of Economics, 128, 1123-1167.

Light, A. (1999): High school employment, high school curriculum, and post-school wages. Economics of Education Review, 18, 291-309.

Light, A. (2001): In-school work experience and the returns to schooling. Journal of Labor Economics, 19, 65-93.

McCoy, S., Smyth, E. (2007): So much to do, so little time: part-time employment among secondary students in Ireland. Work, Employment \& Society, 21, 227-246.

Molitor, C. J., Leigh, D. E. (2005): In-school work experience and the returns to two-year and four-year colleges. Economics of Education Review, 24, 459-468.

Orr, D., Gwos, C., Netz, N. (2011): Social and Economic Conditions of Student Life in Europe. Synopsis of indicators. Bielefeld: Bertelsmann Verlag. 
Pager, D. (2007): The use of field experiments for studies of employment discrimination: contributions, critiques, and directions for the future. Annals of the American Academy of Political and Social Science, 609, 104-133.

Painter II, M. A. (2010): Got a job and keep it! High school employment and adult wealth accumulation. Research in Social Stratification and Mobility, 28, 233-249.

Parent, D. (2006): Work while in high school in Canada: its labour market and educational attainment effects. Canadian Journal of Economics, 39, $1125-1150$.

Rees, D. I., Mocan, H. N. (1997): Labor market conditions and the high school dropout rate: Evidence from New York State. Economics of Education Review, 16, 103-109.

Riach, P. A., Rich, J. (2002): Field Experiments of Discrimination in the Market Place. Economic Journal, 112, 480-518.

Riach, P. A., Rich, J. (2004): Deceptive Field Experiments of Discrimination: Are They Ethical? Kyklos, 57, 457-470.

Ruhm, J. (1997): Is High School Employment Consumption or Investment? Journal of Labor Economics, 15, 735-776.

SONAR (2003): Hoe maken de jongeren de overgang van school naar werk? Basisrapportering Cohorte 1978 (eerste golf). Leuven: Steunpunt WAV.

SONAR (2005): Hoe maken de jongeren de overgang van school naar werk? Basisrapportering Cohorte 1980 (eerste golf). Leuven: Steunpunt WAV.

Spence, M. (1973): Job Market Signaling. Quarterly Journal of Economics, 87, 355-374.

Stiglitz, J. E. (1975): The Theory of "Screening," Education, and the 
Distribution of Income. American Economic Review, 65, 283-300. 
Figure 1. Experimental Identities.

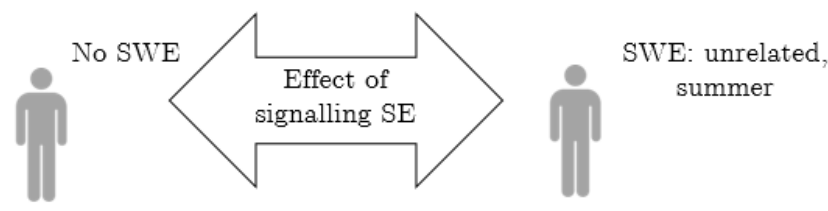

In this figure, "SWE" stands for "student work experience".

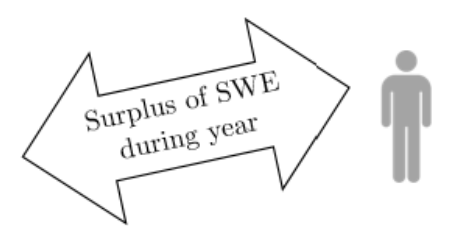

SWE: unrelated, academic year

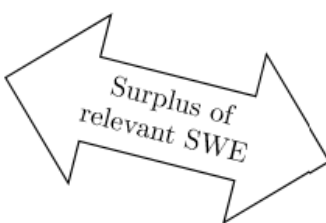

SWE: related summer 
Table 1. Randomisation Statistics.

\begin{tabular}{|c|c|c|c|c|c|c|c|c|c|}
\hline & (1) & $(2)$ & (3) & $(4)$ & $(5)$ & $(6)$ & $(7)$ & $(8)$ & $(9)$ \\
\hline & \multicolumn{4}{|c|}{ Randomised assignment to job application template type } & \multicolumn{4}{|c|}{ Randomised order } & \multirow[b]{2}{*}{ Tota } \\
\hline & $\begin{array}{c}\text { Template } \\
\text { type A }\end{array}$ & $\begin{array}{c}\text { Template } \\
\text { type B }\end{array}$ & $\begin{array}{c}\text { Template } \\
\text { type C }\end{array}$ & $\begin{array}{c}\text { Template } \\
\text { type D }\end{array}$ & $\begin{array}{c}\text { First } \\
\text { application } \\
\text { sent }\end{array}$ & $\begin{array}{c}\text { Second } \\
\text { application } \\
\text { sent }\end{array}$ & $\begin{array}{c}\text { Third } \\
\text { application } \\
\text { sent }\end{array}$ & $\begin{array}{c}\text { Fourth } \\
\text { application } \\
\text { sent }\end{array}$ & \\
\hline No SWE & $59(23.4 \%)$ & $66(26.2 \%)$ & $61(24.2 \%)$ & $66(26.2 \%)$ & $56(22.0 \%)$ & $68(27.0 \%)$ & $57(22.6 \%)$ & $71(28.2 \%)$ & 252 \\
\hline SWE: unrelated, summer & $62(24.6 \%)$ & $68(27.0 \%)$ & $64(25.4 \%)$ & $58(23.0 \%)$ & $65(25.8 \%)$ & $65(25.8 \%)$ & $62(24.6 \%)$ & $60(23.8 \%)$ & 252 \\
\hline SWE: unrelated, academic year & $60(23.8 \%)$ & $54(21.4 \%)$ & $70(27.8 \%)$ & $68(27.0 \%)$ & $70(27.8 \%)$ & $52(20.6 \%)$ & $69(27.4 \%)$ & $61(24.2 \%)$ & 252 \\
\hline SWE: related, summer & $71(28.2 \%)$ & $64(25.4 \%)$ & $57(22.6 \%)$ & $60(23.8 \%)$ & $61(24.2 \%)$ & $67(26.6 \%)$ & $64(25.4 \%)$ & $60(23.8 \%)$ & 252 \\
\hline
\end{tabular}

In this table, "SWE" stands for "student work experience". The presented statistics are frequencies and percentages between parentheses. 
Table 2. Positive Call-Back Rates by Student Work Experience.

\begin{tabular}{|c|c|c|c|c|c|c|}
\hline & $(1)$ & $(2)$ & $(3)$ & $(4)$ & $(5)$ & $(6)$ \\
\hline & \multirow[b]{2}{*}{$\begin{array}{l}\text { No SWE } \\
(\mathrm{N}=252)\end{array}$} & \multicolumn{4}{|c|}{ SWE } & \multirow[b]{2}{*}{ Ratio: $(2) /(1$} \\
\hline & & $\begin{array}{c}\text { All } \\
(\mathrm{N}=756)\end{array}$ & $\begin{array}{l}\text { Unrelated, summer } \\
\qquad(\mathrm{N}=252)\end{array}$ & $\begin{array}{c}\text { Unrelated, academic } \\
\text { year } \\
(\mathrm{N}=252)\end{array}$ & $\begin{array}{l}\text { Related, summer } \\
\qquad(\mathrm{N}=252)\end{array}$ & \\
\hline \multicolumn{7}{|c|}{ A. Positive call-back rates sensu stricto: interview invitation } \\
\hline A.1 All vacancies & 0.067 & 0.062 & 0.063 & 0.063 & 0.059 & $0.922[0.470]$ \\
\hline \multicolumn{7}{|c|}{ A.2 Classified by education level } \\
\hline (Middle-)low & 0.022 & 0.040 & 0.045 & 0.038 & 0.038 & $1.778[1.302]$ \\
\hline (Middle-)high & 0.117 & 0.086 & 0.083 & 0.092 & 0.083 & $0.738^{*}[1.689]$ \\
\hline \multicolumn{7}{|c|}{ A.3 Classified by orientation of occupation } \\
\hline Administrative & 0.036 & 0.033 & 0.029 & 0.029 & 0.043 & $0.933[0.332]$ \\
\hline Industrial & 0.107 & 0.098 & 0.107 & 0.107 & 0.080 & $0.917[0.376]$ \\
\hline \multicolumn{7}{|c|}{ A.4 Classified by contract type mentioned in the vacancy } \\
\hline Permanent & 0.071 & 0.060 & 0.061 & 0.066 & 0.051 & $0.833[0.999]$ \\
\hline Temporary & 0.054 & 0.071 & 0.071 & 0.054 & 0.089 & $1.333[0.621]$ \\
\hline \multicolumn{7}{|c|}{ B. Positive call-back rates sensu lato: any positive reaction } \\
\hline B.1 All vacancies & 0.187 & 0.167 & 0.167 & 0.183 & 0.151 & $0.894[1.322]$ \\
\hline \multicolumn{7}{|c|}{ B.2 Classified by education level } \\
\hline (Middle-)low & 0.110 & 0.081 & 0.091 & 0.098 & 0.053 & $0.711^{*}[1.835]$ \\
\hline (Middle-)high & 0.267 & 0.261 & 0.250 & 0.275 & 0.258 & $0.979[0.225]$ \\
\hline \multicolumn{7}{|c|}{ B.3 Classified by orientation of occupation } \\
\hline Administrative & 0.114 & 0.126 & 0.114 & 0.121 & 0.143 & $1.104[0.761]$ \\
\hline Industrial & 0.277 & 0.217 & 0.232 & 0.259 & 0.161 & $0.785^{* *}[2.191]$ \\
\hline \multicolumn{7}{|c|}{ B.4 Classified by contract type mentioned in the vacancy } \\
\hline Permanent & 0.173 & 0.155 & 0.158 & 0.179 & 0.128 & $0.892[1.117]$ \\
\hline Temporary & 0.232 & 0.208 & 0.196 & 0.196 & 0.232 & $0.897[0.702]$ \\
\hline
\end{tabular}

In this table, "SWE" stands for "student work experience". T-statistics, indicating whether the ratio in Column (6) is significantly different from 1 and based on standard errors corrected for clustering at the vacancy level, are between brackets. ${ }^{*}\left({ }^{*}\right)$ indicates significance at the $10 \%(5 \%)$ significance level. 
Table 3. Positive Call-Back Ratios by Student Work Experience.

(1)

(2)

(3)

No SWE

SWE: unrelated,

SWE: unrelated,

summer

academic year

A. Positive call-back ratios sensu stricto: interview invitation

A.1. SWE: unrelated, summer $\quad 0.941[0.301]$

A.2. SWE: unrelated, academic year $\quad 0.941[0.277]$

$1.000[0.000]$

A.3. SWE: related, summer $0.882[0.534]$

$0.938[0.242]$

$0.938[0.258]$

B. Positive call-back ratios sensu lato: any positive reaction

B.1. SWE: unrelated, summer

$0.894[1.148]$

B.2. SWE: unrelated, academic year

$0.979[0.218]$

$1.095[0.852$

B.3. SWE: related, summer

$0.809 *[1.677]$

$0.905[0.755]$

$0.826[1.516$

In this table, "SWE" stands for "student work experience". The positive call-back ratios are calculated by dividing the positive call-back rate for the experimental identity indicated in the row header by the positive call-back rate for the experimental identity indicated in the column header. T-statistics, indicating whether the ratios are significantly different from 1 and based on standard errors corrected for clustering at the vacancy level, are between brackets. $*$ indicates significance at the $10 \%$ significance level. 
Table 4. The Odds of Positive Call-back: Ordered Logit Estimates.

\begin{tabular}{|c|c|c|c|c|}
\hline & (1) & $(2)$ & $(3)$ & (4) \\
\hline \multirow{2}{*}{ SWE } & 0.876 & 0.873 & 0.864 & 0.854 \\
\hline & $(0.086)$ & $(0.087)$ & $(0.087)$ & $(0.100)$ \\
\hline \multirow{2}{*}{ SWE x SWE during academic year (normalised) } & & 1.108 & 1.116 & 1.140 \\
\hline & & $(0.143)$ & $(0.143)$ & $(0.166)$ \\
\hline \multirow{2}{*}{ SWE x SWE related to field of study (normalised) } & & 0.890 & 0.890 & 0.889 \\
\hline & & $(0.144)$ & $(0.143)$ & $(0.156)$ \\
\hline \multirow{2}{*}{ Job application template type A (normalised) } & & & 1.140 & 0.953 \\
\hline & & & $(0.155)$ & $(0.273)$ \\
\hline \multirow{2}{*}{ Job application template type B (normalised) } & & & 1.129 & 1.117 \\
\hline & & & $(0.173)$ & $(0.193)$ \\
\hline \multirow{2}{*}{ Job application template type $\mathrm{C}$ (normalised) } & & & 1.098 & 0.938 \\
\hline & & & $(0.168)$ & $(0.271)$ \\
\hline \multirow{2}{*}{ First application sent (normalised) } & & & $1.365^{* *}$ & $1.428^{* *}$ \\
\hline & & & $(0.205)$ & $(0.242)$ \\
\hline \multirow{2}{*}{ Second application sent (normalised) } & & & 1.225 & 1.281 \\
\hline & & & $(0.182)$ & $(0.234)$ \\
\hline \multirow{2}{*}{ Third application sent (normalised) } & & & 1.058 & 1.062 \\
\hline & & & $(0.126)$ & $(0.136)$ \\
\hline \multirow{2}{*}{ SWE x SWE in American fast-food restaurant (normalised) } & & & & 1.406 \\
\hline & & & & $(0.626)$ \\
\hline \multirow{2}{*}{ SWE x (Middle-)high educated (normalised) } & & & & 1.218 \\
\hline & & & & $(0.276)$ \\
\hline \multirow{2}{*}{ (Middle-)high educated (normalised) } & & & & $3.432^{* * *}$ \\
\hline & & & & $(1.140)$ \\
\hline \multirow{2}{*}{ SWE x Vacancy for industrial occupation (normalised) } & & & & $0.639^{* *}$ \\
\hline & & & & $(0.137)$ \\
\hline \multirow{2}{*}{ Vacancy for industrial occupation (normalised) } & & & & $3.552^{* * *}$ \\
\hline & & & & $(1.182)$ \\
\hline \multirow{2}{*}{ SWE x Vacancy offering temporary contract (normalised) } & & & & 1.022 \\
\hline & & & & $(0.248)$ \\
\hline \multirow{2}{*}{ Vacancy offering temporary contract (normalised) } & & & & 1.322 \\
\hline & & & & $(0.499)$ \\
\hline
\end{tabular}

In this table, "SWE" stands for "student work experience". All variables except for the one indicating student work experience, are normalised. The variable "SWE in American fast-food restaurant" is normalised by subtracting its mean among the subpopulation of former student workers with a job unrelated to their field of study. The other ones are normalised by subtracting their mean among the subpopulation of all former student workers. The presented statistics are odds ratios based on ordered logistic regression. The presented statistics are odds ratios based on ordered logistic regression The dependent variable is 2 in case the candidate gets immediately invited to a job interview, 1 in case he gets any other positive reaction and 0 in case he gets no (positive) reaction at all. Standard errors, corrected for clustering at the vacancy level, are between parentheses. ${ }^{* *}(* * *)$ indicates significance at the $5 \%(1 \%)$ significance level. 